\title{
ANIMAL TRACTION: NEW OPPORTUNITIES AND NEW CHALLENGES
}

\author{
Arlindo ALMEIDA ${ }^{1}$, João RODRIGUES ${ }^{2}$, Tomás de FIGUEIREDO ${ }^{1}$ \\ ${ }^{1}$ School of Agriculture, Polytechnic Institute of Bragança - Mountain Research Centre (CIMO), \\ PORTUGAL \\ ${ }^{2}$ Portuguese Association of Animal Traction (APTRAN), Mountain Research Centre (CIMO) - School of \\ Agriculture, Polytechnic Institute of Bragança, PORTUGAL \\ E-mail of corresponding author: acfa@ipb.pt
}

Keywords: Mechanization, Draught animal, Impacts, Mountain farming, Sustainable agriculture

\begin{abstract}
In the last one hundred years, tractors with much more power replaced animals all over the world, except in developing countries. Besides the advantage in power, the use of tractors increases agriculture productivity and time efficiency of field operations. Despite the unquestionable advantage of tractors for agriculture performance, in recent years the interest by animal traction is growing, even in developed countries. It is important to understand why. This interest usually is linked to small scale farming, but not only. Environmental concern is one of the most significant reasons, in different aspects: use of working animals as a renewable source of energy; forest management in protected areas to protect soil physical properties related to compaction affected by tillage treatments; field operations in environment protected areas, among others. In old vineyards, but producing a high value output, plant spacing turn animal traction without alternative. The maintenance of the gene pool in domestic animals; the creation of jobs in rural areas, such as farrier, harness maker and implement manufacturer, are also important issues.

New challenges: new implements must be designed and new mechanical solutions achieved.
\end{abstract}

\section{INTRODUCTION}

Animal traction has been used by humans as draught power since the origin of agriculture. With the use of tractors, farmers get access to much more work power and gained a significant increase of productivity and time efficiency in field operations. To have the possibility to realize field operations in the most convenient period of time, is one of the most important achievements of mechanical traction, especially in industrial farms. In developed countries, the use of animal power is usually confined to specific contexts, such as in protected areas (Cerruti, A. et al, 2014). However, due to limited availability to fossil fuels, it is expected an increase of interest of animals for traction.

Other reasons can be pointed out. The use of heavy machinery in forest or agriculture operations can promote severe soil degradation, in particular in mountains regions where soils are generally poor. The most common degradation effects are soil compaction and erosion. In addition, in mountain regions, the number of small farms is significant. In these types of farms, the mechanized operations have high cost effectiveness.

In Europe, field experiments have been carried out under research programs, in order to evaluate the performance and benefits of animal traction $v s$ tractors. We will refer some of them, one focusing in forest management, other in soil tillage. Others interesting conditions for animal traction will be referred.

\section{FOREST MANAGEMENT}

In forestry and in agriculture, mechanical traction substitute animals at a much lower cost and within a period of time suitable for the best conditions for the field operations.

But in certain conditions, in forest, animal systems can offer some benefits over machine systems (Spinelli, R. et al, 2013). Animals represent a clean alternative with low-impact, interesting in protected areas. 
Figure 1, show looging operations using horses, during intermediate cuttings of immature pine trees in a forest managed by the Municipality of Vimioso, northeast of Portugal. Animal traction as gradually been recognized as an important tool for sustainable management of woodlands.

In these conditions (forests in protected areas) operations can require surgical accuracy, such as removing wind-thrown trees with a very little damage to residual trees and causing minimal soil disturbance and compaction.

On this subject R. Spinelli, R. et al, (2013); Magagnotti N. et al, (2011a); Magagnotti N. et al, (2011b) carried out interesting research, comparing economic and environmental performance of animal systems and machine system.

It was verified that: (1) machines need more space for accessing the work place; (2) costeffective mechanized harvesting demands a minimum intensity removal, below which machine becomes a main economic constraint, being animals less dependent on removal intensity; (3) animals (horses in the case) can skid through tight spaces with a very little damage to residual trees.

About this last issue it was concluded (Magagnotti N. et al, 2011a) that tractor skidding is cheaper than horse skidding when extraction distance exceeds $50 \mathrm{~m}$ if the cost of trail building is not accounted. If skidding trails must be built, skidding with one horse is cheaper than tractor skidding until distances exceeds $200 \mathrm{~m}$.

Draught horses represented an advantage in low-intensity cuts, in short extraction distances or when pre-existing trails are not available.

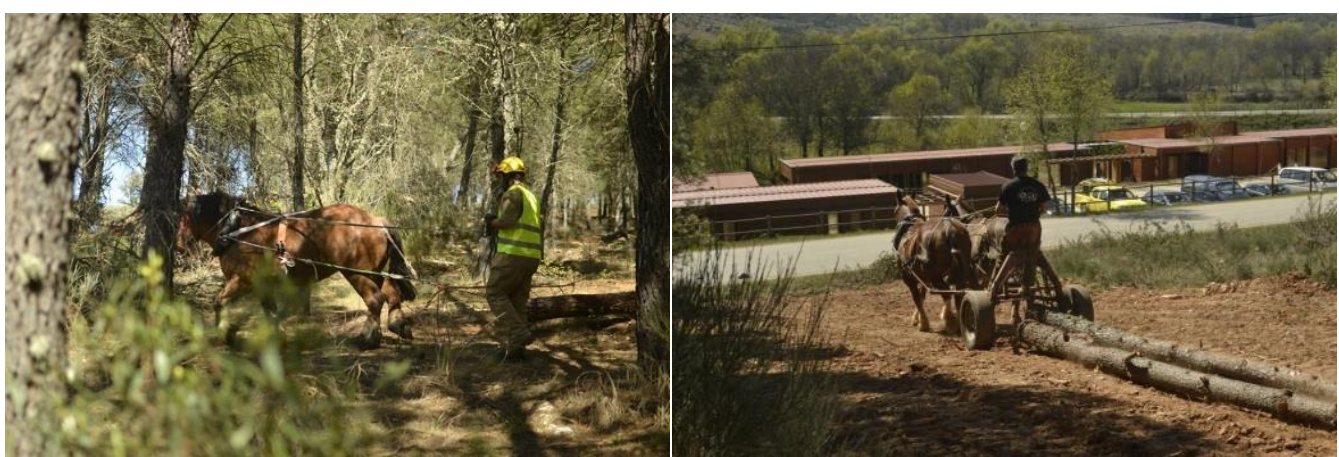

Figure 1. Horse skidding in forest (APTRAN).

\section{SOIL TILLAGE}

In recent years studies have been conducted in Portugal to assess the impacts on soil compaction of tillage operations with tractor pulled equipment and equipment for animal traction.

Soil compaction results from compressive forces applied to compressible soil by machinery wheels combined with tillage operations (García-Tomillo et al, 2017). Draft animal may also cause soil compaction, but a huge gap exists on experimental data (García-Tomillo et al, 2017).

Soil compaction is regarded as one of the most serious form of land degradation caused by conventional farming practices. Compaction alters soil structure by crushing aggregates or combining them in larger units, increase soil bulk density and decrease the 
number of coarse pores (García-Tomillo et al, 2017). The economic cost and the difficulty to be detected, make soil compaction a serious risk for food security.

The long-term use of mechanical tillage equipment, such as mouldboard ploughs and rotavators, results in a compact soil difficult to be penetrated by crop roots.

Actually, animal traction is an option seen with increasing potential to contribute to sustainable agriculture, especially in mountain areas. However, a gap of information exists in the context of mountain agriculture.

The research mentioned, carried on by García-Tomillo et al (2017), aim to compare tillage operations performed with two types of draft animals, cows (a pair) and donkeys (a pair), focusing on the effects on soil physical properties related to soil compaction, and testing the performance of Electrical Resistivity Tomography (ERT) in detecting changes in soil physical properties affected by tillage treatments.

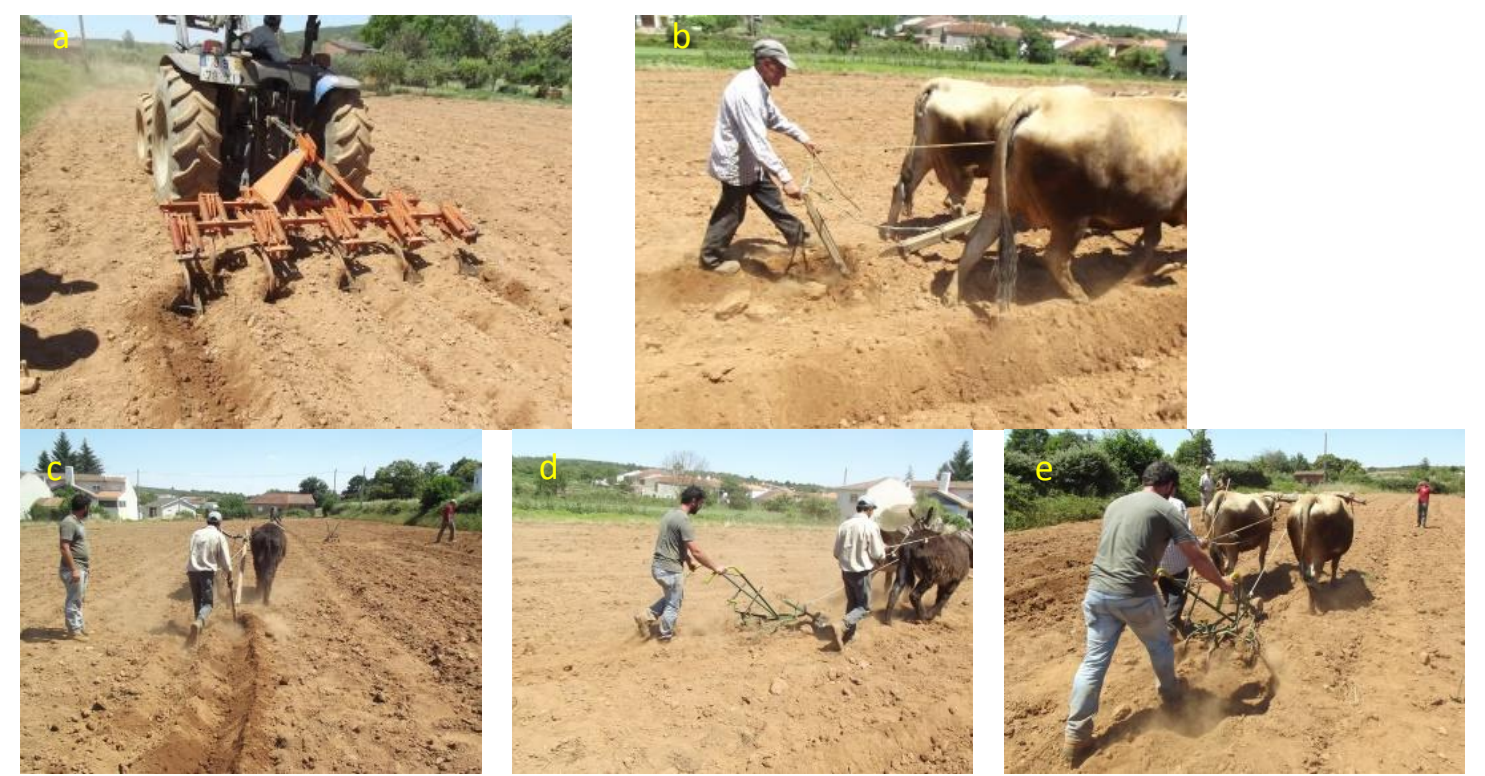

Figure 2. Cultivator pulled by tractor (a); Roman plough pulled by cows (b) and by donkeys (c); Cultivator pulled by donkeys (d) and by cows (e).

Three different implements were considered (Figure 2): for animal traction a Roman plough and a 5 tine cultivator; for tractor a 9 tine cultivator. Tractor weight was $2745 \mathrm{~kg}$; animal weight was approximately $700 \mathrm{~kg}$ for each donkey and $1200 \mathrm{~kg}$ for each cow. Weight of cultivator pulled by tractor was $360 \mathrm{~kg}$. Weight of equipment pulled by animals was $30 \mathrm{~kg}$ each (cultivator and Roman plough).

Results also show that the reduction in soil porosity after tillage was more pronounced in tractor plots than in the animal traction ones, the lower effect being measured in donkey's plots. As well, soil moisture redistribution and retention were more affected by tillage in the former than in the latter plots. These promising preliminary results point out, however, the need for future research (Figueiredo et al, 2017).

\section{OTHER OPPORTUNITIES}

Animal traction can have an important role in other specific conditions, not yet under scientific research. 

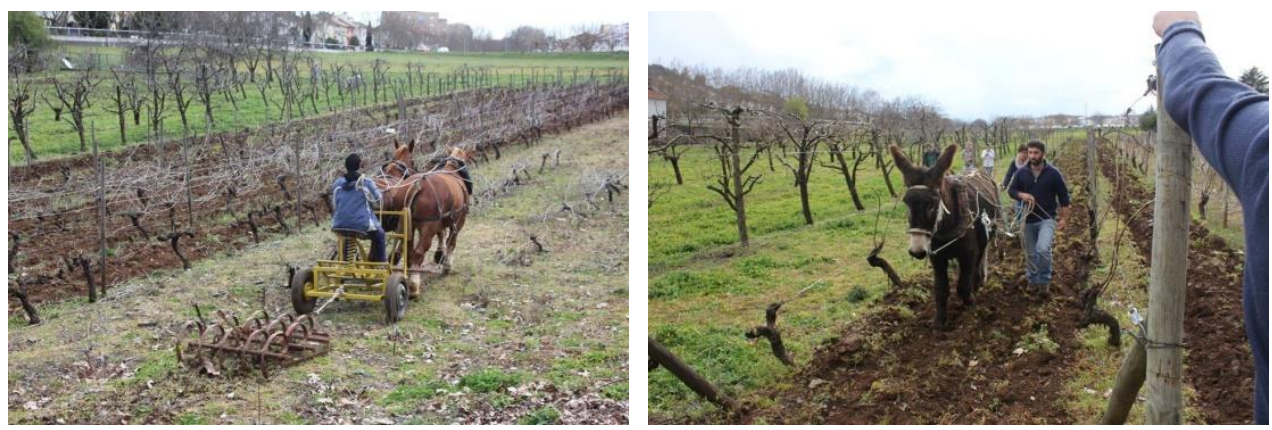

Figure 3. Animal working in vineyards

Working vines with animals never totally disappeared. It is the case of old vineyards producing a high value output with short plant spacing or in terraces or steep slopes, turn animal traction without alternative (Figure 3). That is happening in Douro River Valley (Oporto wine producer region) in Portugal, in France - Burgundy or Bordeaux regions, or in Spain - Ribeira Sacra region.

Vineyards in the School of Agriculture, Polytechnic Institute of Bragança, where animal traction has been used on a regular basis to demonstrate its potential (Figure 3). Important note: the use of a Zamorano-Leones donkey, as a way to promote local and regional breeds as working animals.

When working in greenhouses animal traction can be useful. Figure 4 show greenhouse work with horses, using light modern implements for vegetable production.

Animal traction can have a positive role in more remote regions, usually in mountains, were the creation or preservation of jobs, such as farrier, harness maker and implement manufacturer, represents an opportunity for young people, avoiding the emigration.

The maintenance of the gene pool in domesticated animals, is not a minor issue.

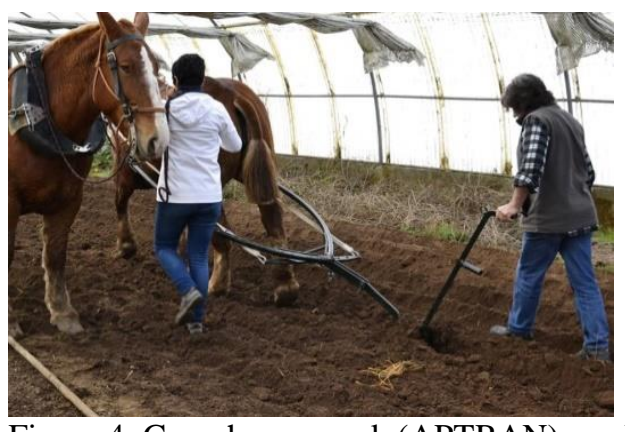

Figure 4. Greenhouse work (APTRAN)

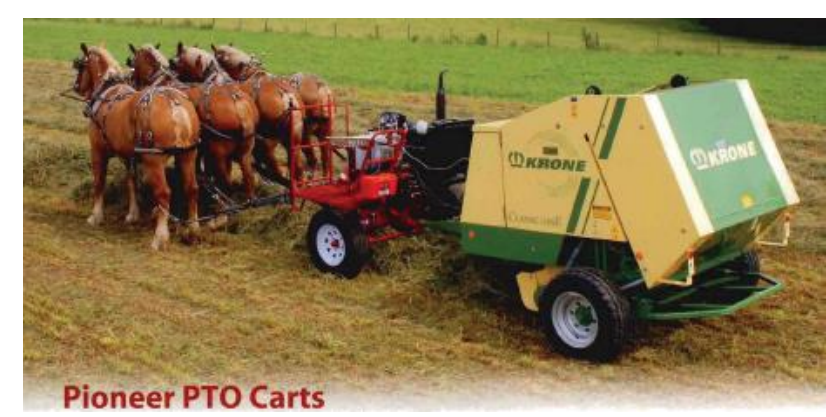

Figure 5. Forecart with engine PTO (Pioneer catalog 2014)

\section{CHALLENGES}

These opportunities represent new challenges. Old equipment from the first half of the twentieth century is becoming hard to find, or replacement parts difficult to find.

Remanufacturing older equipment with new design, including different models of forecarts to be used with different implements made for small tractors is a challenge that has been answered by manufactures in United States and Central Europe. Some of the new forecarts have a power take-off (PTO) drive from wheels or from a motor (Figure 5). Getting power to PTO from wheels is a better solution, but needs an additional research in order to get enough torque for the machinery used. 
New solutions based on electric energy assistance are referred by Rodrigues et al (2017). The energy produced by braking friction on the downhill travel is stored in a battery and returned to electric motors to assist animals on uphill travel or when pulling heavy loads.

\section{CONCLUSIONS}

Animal power is usually considered as a sign of underdevelopment. A negative perception still exists regarding this source of energy (www.fectu.org). This view is changing, especially in low intensity agriculture systems, in protected areas and in mountainous regions. Development is based in economy, but also in environmental preservation, improvement of population quality of live and the sustainability of natural resources for agriculture and forest production.

This interest is growing in scientific community, which is an important step in the process. The disinterest that has been given to working animals has now negative consequences that will need to be overcome. One of them is the difficulty of finding drivers for animals and trained animals.

More research is needed on this subject, focusing for instance in costs. Costs for work and maintain animals (horses, cows, donkeys, and so on) vs tractors.

\section{REFERENCES}

Cerutti, A., Calvo, A., Bruun, S. (2014). Comparison of the environmental performance of light mechanization and animal traction using a modular LCA approach. Journal of Cleaner Production 64:396-403.

García-Tomillo A., Figueiredo T., Almeida A., Rodrigues J., Dafonte J., Paz González A., Nunes J., Hernandez Z. (2017). Comparing effects of tillage treatments performed with animal traction on soil physical properties: preliminary experimental results. Open Agriculture; 2:317-328.

Magagnotti N., Spinelli R. (2011a) Financial and energy cost of low-impact wood extraction in environmentally sensitive areas. Ecological Engineering 37:601-606.

Magagnotti N., Spinelli R. (2011b). Integrating Animal and Mechanical Operations in protected areas. Croat. J. for eng. 32 2:489-499.

Rodrigues, J.B., Schlechter, P. Spychiger, H. Spinelli, R. Oliveira, N., Figueiredo T. (2017). The XXI century mountains: sustainable management of mountainous areas based on animal traction. Open Agriculture 2:300-307.

Spinelli R., Lombardini C., Magagnotti N. (2013). Salvaging windthrown trees with animal and machine systems in protected areas. Ecological Engineering 53:61-67.

Figueiredo, T., García-Tomillo, A., Almeida, A., Rodrigues, J., Paz-Gonzalez, A., Dafonte, J, Nunes, J., Hernández, Z., Bandeira, D. (2017). Effect on soil hydraulic properties of tillage operations with animal traction: results of an experiment in NE Portugal. In IX Iberian Congress on agro-engineering -

Bragança, Portugal (in press) 8 p. 